\title{
Characterization of Trace Amounts of Odorants (Sulfur Compounds, Oxygenates, Hydrocarbons, Phenols and Lower Fatty Acids) in Air in an ICU Room
}

\author{
Yasuyuki HOSHIKA
}

Department of Hygiene, Shinshu University School of Medicine, Matsumoto

\begin{abstract}
Characterization of trace amounts of odorants in air in an ICU room (ca. $257 \mathrm{~m}^{2}$ ) was carried out by gas chromatography and atmospheric pressure ionization-mass spectrometry (API-MS) . The concentrations and odor recognition threshold values of the detected odorants, acetaldehyde, ethanol, n-butyric acid, iso-valeric acid and n-valeric acid are as follows: 44.7 $\mathrm{ppb}$ and $15 \mathrm{ppb} ; 19710 \mathrm{ppb}$ and $6100 \mathrm{ppb} ; 0.50 \mathrm{ppb}$ and $0.4 \mathrm{ppb} ; 0.45 \mathrm{ppb}$ and $0.4 \mathrm{ppb} ; 0.67 \mathrm{ppb}$ and $0.5 \mathrm{ppb}$, respectively. The detected concentrations of these odorants were significantly higher than the odor recognition threshold values. The compounds may, therefore, be responsible for perception of such odors as mixed odors, body odor, and faint or recognizable alcoholic odor, disinfectant odor, and sour, pungent, and goaty odors.
\end{abstract}

Key words : ICU room air, Odorants, Oxygenates, Lower fatty acids, Gas chromatography and atmospheric pressure mass spectrometry

\section{Introduction}

The determination of important volatile compounds (odorants) responsible for many diseases and intoxications, and their recognition can provide diagnostic clues, guide laboratory evaluation and affect the choice of immediate therapy. However, analysis of metabolites or volatile components from expired air (breath) and urine is not so widely employed. Furthermore, the metabolic pathways are generally unknown. Detection of medically important characteristic odors remains a chemical skill. Such detection may be useful in the diagnosis of certain diseases or in the identification of ingested substances. Such odors derived from skin, sputum, vomitus, stool, vaginal discharge, pus, and even cerumen may have diagnostic value ${ }^{1,2)}$.

In Japan, the Offensive Odor Control Law was enacted in $1972^{3)}$. As listed in Table 1 , as of 1989, there were 12 controlled odorants: ammonia, methyl mercaptan, hydrogen sulfide, dimethyl sulfide, dimethyl disulfide, trimethyl amine, acetaldehyde, styrene, propionic acid, n-butyric acid, $n$-valeric acid and iso-valeric acid. Permissible concentrations of these substances in ambient air in factories range from $0.0009 \mathrm{ppm}$ ( $\mathrm{n--}$ valeric acid) to $5 \mathrm{ppm}$ (ammonia). These concentrations correspond to 2.5 to 3.5 in the sixodor intensity grade (non-odor, barely perceptible or detectable, faint or recognizable, easily noticed, strong, very strong), according to the Katz and Talbert scale ${ }^{4)}$.

Of the 12 odorants, ammonia, hydrogen sulfide and trimethyl amine are also controlled in factory exhaust gas.

Summer reported that hospitals and similar institutions require local deodorization in such

Reprint requests to : Yasuyuki HOSHIKA, Department of Hygiene, Shinshu University School of Medicine, 3-1-1, Asahi, Matsumoto-shi, Nagano, 390, Japan 
Jpn. J. Hyg., Vol.48, No.3, August 1993

Table 1 Odorants and concentrations controlled in 1989 in Japan

\begin{tabular}{l|l|l|l|l|l|l|l|l}
\hline Odorant & \multicolumn{1}{|c|}{1} & \multicolumn{1}{|c|}{2} & \multicolumn{1}{|c|}{2.5} & \multicolumn{1}{|c|}{3} & 3.5 & 4 & 5 \\
\hline Ammonia & 0.1 & 0.6 & 1 & 2 & 5 & $1 \times 10$ & $4 \times 10$ \\
Methyl mercaptan & 0.0001 & 0.0007 & 0.002 & 0.004 & 0.01 & 0.03 & 0.2 \\
Hydrogen sulfide & 0.0005 & 0.006 & 0.02 & 0.06 & 0.2 & 0.7 & 8 \\
Dimethyl sulfide & 0.0001 & 0.002 & 0.01 & 0.04 & 0.2 & 0.8 & 2 \\
Dimethyl disulfide & 0.0003 & 0.003 & 0.009 & 0.03 & 0.1 & 0.3 & 3 \\
Trimethyl amine & 0.0001 & 0.001 & 0.005 & 0.02 & 0.07 & 0.2 & 3 \\
Acetaldehyde & 0.002 & 0.01 & 0.05 & 0.1 & 0.5 & 1 & $1 \times 10$ \\
Styrene & 0.03 & 0.2 & 0.4 & 0.8 & 2 & 4 & $2 \times 10$ \\
Propionic acid & 0.002 & 0.01 & 0.03 & 0.07 & 0.2 & 0.4 & 2 \\
n-Butyric acid & 0.00007 & 0.0004 & 0.001 & 0.002 & 0.006 & 0.02 & 0.09 \\
n-Valeric acid & 0.0001 & 0.0005 & 0.0009 & 0.002 & 0.004 & 0.008 & 0.04 \\
iso-Valeric acid & 0.00005 & 0.0004 & 0.001 & 0.004 & 0.01 & 0.03 & 0.3 \\
\hline
\end{tabular}

The concentration limits () in ambient factory air range from $0.0009 \mathrm{ppm}$ (n-valeric acid) to $5 \mathrm{ppm}$ (ammonia). These concentrations correspond to 2.5 to 3.5 in the six odor intensity categories (no odor, barely perceptible or detectable, faint or recognizable, easily noticed, strong, very strong), according to the Katz and Talbert scale.

areas as selected beds in incurable wards, post mortem rooms and pathology laboratories ${ }^{5)}$.

However, very little knowledge has been obtained about the chemical nature of the odorants in practical ICU room air or odor-polluted air.

In this paper, the use of simple and sensitive gas chromatography and API-MS to determine trace amounts of odorants in the air of the Shinshu University School of Medicine Hospital ICU room is described.

\section{Experimental}

\section{ICU room.}

This room (Fig. 1) is approximately $257 \mathrm{~m}^{2}$ in area on one floor, with 5 beds, including one private room $\left(13 \mathrm{~m}^{2}\right)$, and has an air-flow rate of $3000 \mathrm{~m}^{3} / \mathrm{hr}$. A re-cycling air conditioning system is used to purge the room air by passing it through an ultra hepta-filter system.

The persons and chemicals used in the ICU room are listed in Table 2 .

\section{Reagents for analyses.}

Hydrogen sulfide (minimum purity $99.6 \%$ ) was obtained from Matheson Gas Products, East Rutherford, NJ, USA.Standard hydrogen sulfide gas was prepared by diluting pure gas (0.1-10 $\mathrm{ml})$ in a 101 Tedlar bag filled with pure nitrogen gas (more than $99.9995 \%$ pure).

Acetaldehyde (minimum purity $99.5 \%$ ) was obtained from E. Merck (Darmstadt, Germany); methanol, ethanol, propanol and acetone were obtained from Katayama Chemical and Tokyo Kasei Kogyo, Tokyo, Japan. A standard solution containing a mixture of the five oxygenates was prepared by dissolving $10 \mu \mathrm{l}$ of each in $10 \mathrm{ml}$ of distilled water.

The standard gases of several hydrocarbons were prepared by evaporating pure liquid standard reagents $(1 \mu \mathrm{l})$ in a 21 Pyrex glass sampling bottle filled with pure nitrogen gas. The hydrocarbons were obtained from Katayama Chemical Industries, Tokyo, Japan.

Phenol (more than 98\% pure) was obtained from Wako Pure Chemical Industries, Tokyo, Japan and a standard solution was prepared by dissolving $3.4 \mathrm{mg}$ in $10 \mathrm{ml}$ of ethanol.

The six lower fatty acids were obtained from Katayama Chemical Industries, Tokyo, Japan. Standard solutions of the lower fatty acids were prepared by dissolving each acid in $10 \mathrm{ml}$ of distilled water to a concentration of $0.1 \mathrm{mmol} / 10$ $\mathrm{ml}$ of solvent. All other reagents were of guaranteed or analytical reagent grade. 


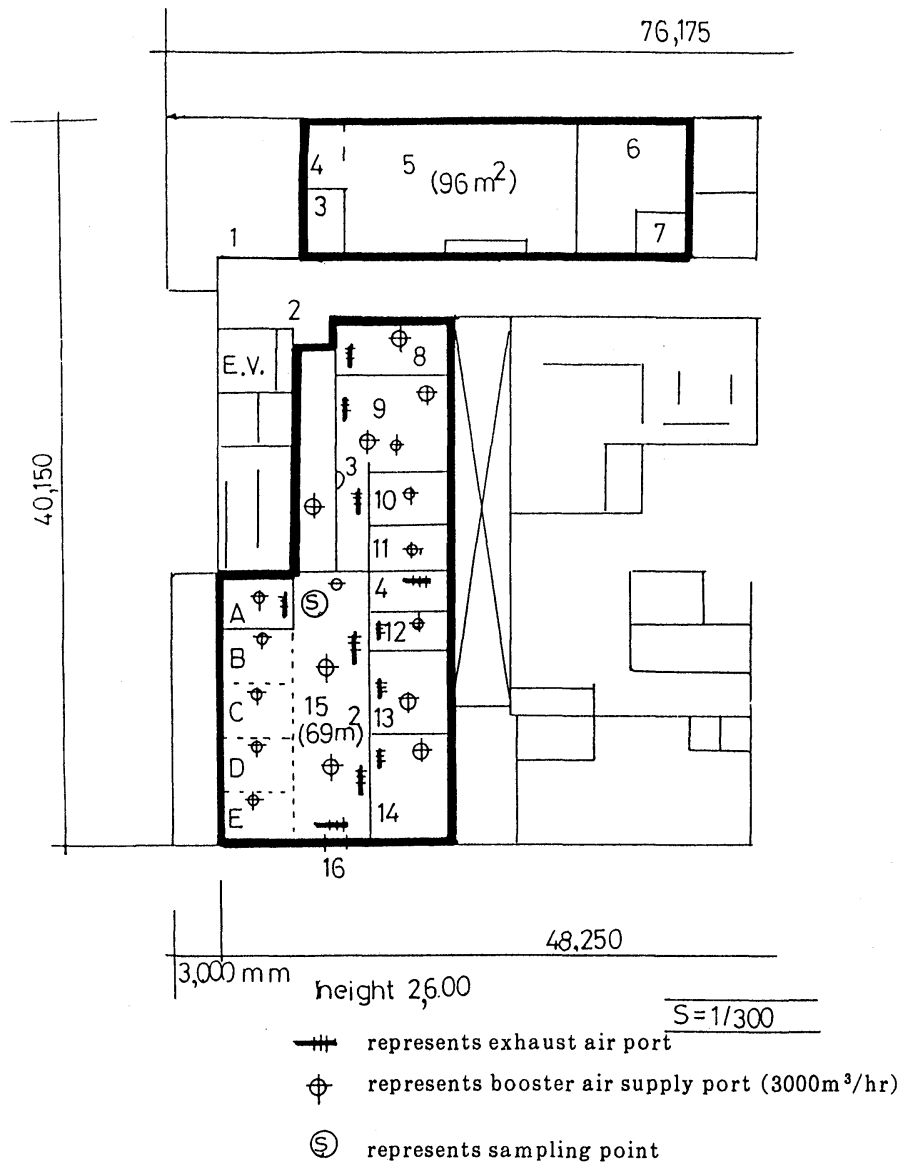

Fig. 1 Schematic diagram of the Shinshu University School of Medicine Hospital ICU $\left(\right.$ ca. $\left.257 \mathrm{~m}^{2}\right)$ room

1. Auto door; 2. Entrance; 3. Information counter $\left(11 \mathrm{~m}^{2}\right) ; 4$. Dirt room $\left(10 \mathrm{~m}^{2}\right)$;

5. Consultation room, medical examination $\left(96 \mathrm{~m}^{2}\right) ; 6$. X-ray room $\left(39 \mathrm{~m}^{2}\right) ; 7$. Installation room $\left(8 \mathrm{~m}^{2}\right) ; 8$. Duty room $\left(19 \mathrm{~m}^{2}\right) ; 9$. Seminar room $\left(32 \mathrm{~m}^{2}\right) ; 10$. Meeting room $\left(16 \mathrm{~m}^{2}\right) ; 11$. Locker room $\left(14 \mathrm{~m}^{2}\right) ; 12$. Laboratory testing room $\left(10 \mathrm{~m}^{2}\right) ; 13$. Pretreatment room $\left(18 \mathrm{~m}^{2}\right) ; 14$. Storehouse $\left(28 \mathrm{~m}^{2}\right) ; 15$. Sick room $\left(69 \mathrm{~m}^{2}\right) ; 16$. Emergency room; A: Private room $\left(13 \mathrm{~m}^{2}\right)$; B-E: Beds $\left(\right.$ each $\left.9 \mathrm{~m}^{2}\right)$

Table 2 Persons and chemicals used in the Shinshu University School of Medicine Hospital ICU room (Oct. 30, 1990)

\begin{tabular}{|c|c|c|}
\hline Patients & \multicolumn{2}{|l|}{$\mathrm{n}=5$} \\
\hline Nurses & \multicolumn{2}{|l|}{$\mathrm{n}=8$} \\
\hline Doctors & \multicolumn{2}{|l|}{$\mathrm{n}=8$} \\
\hline \multicolumn{3}{|c|}{ Chemicals } \\
\hline \multicolumn{2}{|c|}{ Ethanol for Disinfection $76.9-81.4 \mathrm{v} / \mathrm{v} \%$} & $500 \mathrm{ml} \times 20 /$ week \\
\hline \multicolumn{2}{|c|}{ Sterihyde 20 Glutaraldehyde } & $500 \mathrm{ml} \times 2 / \mathrm{w}$ \\
\hline \multicolumn{3}{|c|}{$\begin{array}{l}\text { Others, Benzine } 500 \mathrm{ml} \times 1 / \text { day } ; \text { Hybiten } \\
\text { Osban alcohol } 20 \mathrm{l} \times 2 / \mathrm{w} \text {. and } \mathrm{Me}\end{array}$} \\
\hline
\end{tabular}




\section{Gas chromatography.}

The gas chromatographs used were a Shimadzu Model GC3BF and GC4CMFFp (Kyoto, Japan) equipped with a flame ionization detector (FID) and a flame photometric detector (FPD), respectively and a Shimadzu Chromatopac C-R4A and $\mathrm{C}-\mathrm{RlB}$ for quantitative analysis and retention time determinations, respectively. Gas chromatography was used for determination of trace amounts of the odorants from the ICU room air using two preconcentration methods, namely, cold trapping with liquid oxygen for sulfur compounds, oxygenates and hydrocarbons, and room temperature adsorption trapping with porous polymer beads, such as Tenax-GC for phenols. Then thermal extraction in the gas phase under nitrogen carrier gas flow was carried out to eliminate the lower hydrocarbons in the sample that were condensed on the Tenax-GC. The Tenax-GC adsorption precolumn, which collected sample gases, was connected to an XE-60 introductory precolumn (1\% XE-60 on Chromosorb W, AW. DMCS, 80/100 mesh, $10 \mathrm{~cm} \times 4 \mathrm{~mm}$ i.d. glass) in series and used at room temperature. The thermal extraction in the gas phase of the sample gases including phenol on the Tenax-GC precolumn connected to the XE-60 precolumn was carried out by heating the Tenax-GC precolumn to $200^{\circ} \mathrm{C}$ for $1.5 \mathrm{~min}$, while the nitrogen carrier gas flowed at $75 \mathrm{ml} / \mathrm{min}$ and the XE- 60 precolumn was kept at room temperature. This thermal extraction process in the gas phase was necessary for the elimination of the large amounts of lower molecular components such as hydrocarbons which interfered with the analysis of the trace phenols by FID.

The XE- 60 precolumn preconcentrated the phenols in the sample gases and transferred them into the carrier gas (nitrogen) line of the GC and, after $30 \mathrm{sec}$. at room temperature, this precolumn was heated to $180^{\circ} \mathrm{C}$ for $40 \mathrm{sec}$.

The Tenax-GC trapping precolumn was preconditioned using a column oven temperature of $250{ }^{\circ} \mathrm{C}$ for $4 \mathrm{hr}$ and a constant flow rate of nitro- gen $(50 \mathrm{ml} / \mathrm{min})$. The XE-60 precolumn was also preconditioned at $230^{\circ} \mathrm{C}$ for $4 \mathrm{hr}$ with a constant flow rate of nitrogen $(50 \mathrm{ml} / \mathrm{min})$. Breakthrough process of phenol on the XE-60 precolumn occured after heating at more than $50^{\circ} \mathrm{C}$ for $7 \mathrm{~min}$ (nitrogen $50 \mathrm{ml} / \mathrm{min}$ ); therefore phenol was quantitatively recovered from the XE-60 precolumn in the thermal extraction process in the gas phase.

For the lower fatty acids, chemical reaction by $\mathrm{Sr}(\mathrm{OH})_{2}$ on glass beads also followed acidbase chemical reaction for regeneration with formic acid.

The other GC operating conditions are given in Table 3.

The sample gases from sulfur compounds, oxygenates and hydrocarbons were collected directly in the precolumn by cold trapping with liquid oxygen. The sampling rate was about 0.4 liter/min. The sample gases from phenol and lower fatty acids were collected directly in the adsorption trapping precolumn at room temperature at a sampling rate of about $0.4 \mathrm{l} / \mathrm{min}$. A vacuum pump (Mini-Vac Model PS-05, Yamato, Tokyo, Japan, maximum $5 \mathrm{l} / \mathrm{min}$ ) and a gas meter (T-3 dry test gas meter, ChubushinagawaSeisakusho, Tokyo, Japan, 1 l/rev) were used for sample preparation. Some of the details of the gas chromatography and preconcentration have been reported in previous papers ${ }^{6 \sim 11)}$.

The identification of all odorants was carried out by comparison of the retention times of the samples with those of known standard compounds. The peaks due to carbonyl compounds such as acetaldehyde and acetone were identified by the disappearance method using a reaction precolumn of 2,4-dinitrophenylhydrazine $(0.05$ g) - ortho phosphoric acid $(0.1 \mathrm{ml})$ on glass beads (30/60 mesh $5 \mathrm{~g} \mathrm{Wako})^{10 \sim 12)}$.

The amounts of odorants present were determined from calibration graphs for known standard compounds, i.e., concentration volumes, 0.005-50 1; detection limits, 0.005-2 ppb; time required for analysis (including the sampling time), less than about $40 \mathrm{~min}$; precision (as the 
Jpn. J. Hyg., Vol.48, No.3, August 1993

Table 3 Operating conditions for gas chromatography

\begin{tabular}{|c|c|c|c|c|c|}
\hline conditions & 1 & 2 & 3 & 4 & 5 \\
\hline compound & $\begin{array}{l}\text { sulfur } \\
\text { compounds }\end{array}$ & oxygenates & hydrocarbons & phenol & lower fatty acids \\
\hline preconcentration & cold trapping & cold trapping & cold trapping & $\begin{array}{l}\text { adsorption } \\
\text { reconcentration }\end{array}$ & chemical reaction \\
\hline packing & & & & & \\
\hline main & $\begin{array}{l}25 \% \text { TCEP on } \\
\text { Shimalite (AW, } \\
\text { DMCS) } 80 / 100 \\
\text { mesh }\end{array}$ & $\begin{array}{l}\text { Porapak Q } \\
80 / 100 \text { mesh }\end{array}$ & $\begin{array}{l}5 \% \text { SP- } 1200+ \\
1.75 \% \text { Bentone } 34 \\
\text { on Chromosorb } \\
\text { W (AW, DMCS) } \\
80 / 100 \text { mesh }\end{array}$ & $\begin{array}{l}0.1 \% \text { SP }-1000 \text { on } \\
\text { Carbopack C } \\
80 / 100 \text { mesh }\end{array}$ & $\begin{array}{l}0.3 \% \mathrm{FFAP}_{+} \\
0.3 \% \mathrm{H}_{3} \mathrm{PO}_{4} \text { on } \\
\text { Carbopack B } \\
60 / 80 \text { mesh }\end{array}$ \\
\hline precolumn & $\begin{array}{l}\text { 25\% TCEP } \\
\text { Shimalite } \\
\text { (DMCS) } 80 / 100 \\
\text { mesh }\end{array}$ & $\begin{array}{l}\text { (1) Chromosorb W } \\
\text { (AW, DMCS) } \\
80 / 100 \text { mesh } \\
\text { (2) } 1 \% 2,4-\mathrm{DNP}+ \\
2 \% \mathrm{H}_{3} \mathrm{PO}_{4} \text { on } \\
\text { glass beads } \\
30 / 60 \text { mesh }\end{array}$ & $\begin{array}{l}\text { Chromosorb W } \\
\text { (AW, DMCS) } \\
80 / 100 \text { mesh }\end{array}$ & $\begin{array}{l}\text { (1) Tenax-GC } \\
60 / 80 \text { mesh } \\
\text { (2) } 1 \% \text { XE-60 on } \\
\text { Chromosorb W } \\
\text { (AW, DMCS) } \\
\text { 80/100 mesh }\end{array}$ & $\begin{array}{l}1 \% \mathrm{Sr}(\mathrm{OH})_{2} \text { on } \\
\text { glass beads } \\
15 / 28 \text { mesh }\end{array}$ \\
\hline column size & & & & & \\
\hline $\begin{array}{l}\text { main column } \\
\text { (glass) }\end{array}$ & $3 \mathrm{~m} \times 3 \mathrm{~mm} \mathrm{i.d}$ & $1.7 \mathrm{~m} \times 3 \mathrm{~mm}$ i.d. & $3 \mathrm{~m} \times 3 \mathrm{~mm}$ i.d. & $2 \mathrm{~m} \times 3 \mathrm{~mm}$ i.d. & $1.5 \mathrm{~m} \times 3 \mathrm{~mm}$ i.d. \\
\hline $\begin{array}{l}\text { precolumn } \\
\text { (glass) }\end{array}$ & $18 \mathrm{~cm} \times 4 \mathrm{~mm}$ & $31 \mathrm{~cm} \times 4 \mathrm{~mm}$ & $31 \mathrm{~cm} \times 4 \mathrm{~mm}$ & $\begin{array}{l}\text { (1) } 10 \mathrm{~cm} \times 4 \mathrm{~mm} \\
\text { (2) } 10 \mathrm{~cm} \times 4 \mathrm{~mm}\end{array}$ & $2 \mathrm{~cm} \times 5 \mathrm{~mm}$ \\
\hline $\begin{array}{l}\text { temperature } \\
\text { main column }\end{array}$ & $50^{\circ} \mathrm{C}$ & 175 & 60 & 220 & 200 \\
\hline precolumn & $\begin{array}{l}-183^{\circ} \mathrm{C} \text { to } 60 \\
(1 \mathrm{~min})\end{array}$ & $\begin{array}{l}-183 \text { to } 200 \\
(2 \mathrm{~min})\end{array}$ & $\begin{array}{l}-183 \text { to } 200 \\
(2 \mathrm{~min})\end{array}$ & $\begin{array}{l}\text { (1) } 25 \text { to } 200 \\
\text { (1 min) } \\
\text { (2) } 25 \text { to } 180 \\
\text { (40sec) }\end{array}$ & 200 \\
\hline inj. \& det. & $100(200){ }^{\circ} \mathrm{C}$ & 220 & 100 & 250 & 250 \\
\hline carrier gas $\mathrm{N}_{2}$ & $40 \mathrm{ml} / \mathrm{min}$ & 35 & 35 & 75 & 40 \\
\hline $\mathrm{H}_{2}$ & $40 \mathrm{ml} / \mathrm{min}$ & 50 & 50 & 50 & 50 \\
\hline air & $40 \mathrm{ml} / \mathrm{min}$ & 1000 & 1000 & 1000 & 1000 \\
\hline detector & FPD & FID & FID & FID & FID \\
\hline
\end{tabular}

coefficient of variation or relative standard deviation), less than about $10 \%$. Such sensitivity and precision are suitable for use in odor pollution analysis.

API-MS.

The API-MS technique was utilized for direct flow analysis, which was carried out by direct introduction of sample gas to the ion source of the instrument. This new technique is also used for real-time or continuous analysis during rapid scanning and has been shown to be a highly sensitive method for detecting various compounds (at ppm-ppb-ppt levels) in gaseous samples ${ }^{13 \sim}$ 18).

The API-MS spectrometer used was a Hitachi Tokyo Electronics Model UG-12360-P (Tokyo,
Japan) based on a positive ion-mass spectrometry system, combined with API controlled by a Hewlet Packard 9000-236 computer. The optimum conditions for this instrument are as follows: gas sample introduction flow-rate, 0.3 1/min; initial mass, 2; final mass, 200; scanning speed, $1.6 \mathrm{~ms}$; repeat, 2; ion source temperature, $140^{\circ} \mathrm{C}$; SGAIN, $1 \times 10^{-8}(\mathrm{~A} / \mathrm{V})$; VGAIN , 1 - 10; normal mode, 3 min; MID peak, 8 ch - $1200 \mathrm{sec}$.; SEM, $1.8 \mathrm{kV}$; discharge current, $1 \mu \mathrm{A}$ : vacuum, $7 \times 10^{-6}$ Torr. ; discharge voltage, $2 \mathrm{kV}$.

\section{Monitoring of $\mathrm{O}_{2}, \mathrm{CO}, \mathrm{CO}_{2}$}

The monitoring instrument used for $\mathrm{O}_{2}$ and CO was a Riken Keiki Model GX-82 (Gas Man) and $\mathrm{CO}_{2}$ was monitored by a portable $\mathrm{CO}_{2}$ indicator (Riken Keiki, Tokyo, Japan, Model 
RI-411A) .

Sensory testing.

This was carried out by directly sniffing the room air.

A panel of 18 trained nurses from the ICU division was used on alternative days for determining odor quality and odor intensity .

\section{Results and Discussion}

\section{Monitoring data of $\mathrm{O}_{2}, \mathrm{CO}$ and $\mathrm{CO}_{2}$}

Figure 2 shows the data for $\mathrm{O}_{2}, \mathrm{CO}$ and $\mathrm{CO}_{2}$ monitored in the ICU room on Oct. 30, 1990 at $3: 45$ p.m. $\left(28{ }^{\circ} \mathrm{C}, 40 \%\right.$ humidity $)$ and Dec. 27 , 1990 from $3: 20$ p.m. to $4: 20$ p.m. $\left(28{ }^{\circ} \mathrm{C}, 30 \%\right.$ humidity). The concentrations of $\mathrm{O}_{2}$ were 20.3 to $21.2 \%$ and those of $\mathrm{CO}_{2} 350$ to $650 \mathrm{ppm}$, while CO range from 6 to $30 \mathrm{ppm}$. It is well known that the TLV value of $\mathrm{CO}$ for $8 \mathrm{hr}$ (ACGIH recommendation) is $50 \mathrm{ppm}$ in general room air.

Typical gas chromatograms (Sample taken on Dec. 27, 1990, 3:22p.m.-3:25p.m.)

Figure 3 shows typical gas chromatograms of sulfur compounds in the ICU room air.

As shown in Fig. 3, at least three sulfur com-

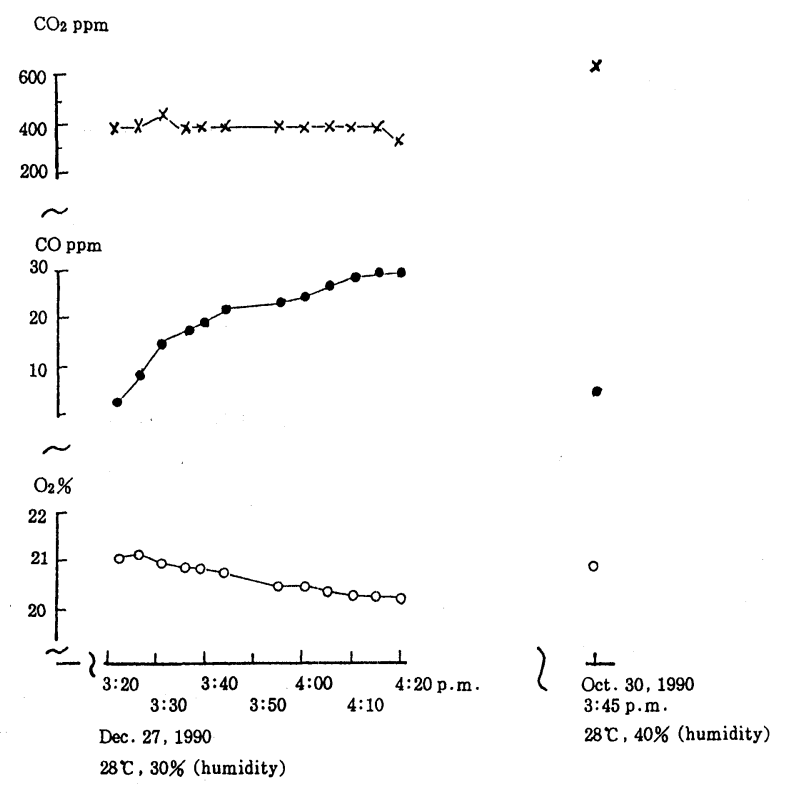

Fig. $2 \mathrm{O}_{2}, \mathrm{CO}$ and $\mathrm{CO}_{2}$ in the Shinshu University School of Medicine Hospital ICU room air

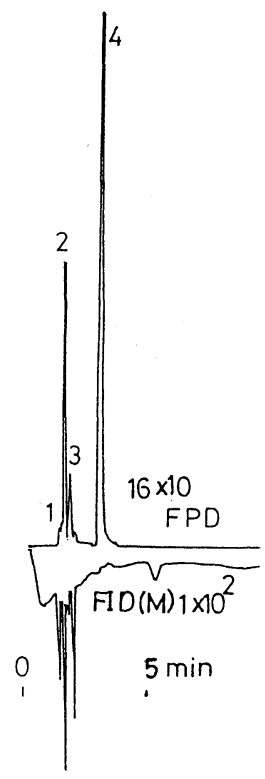

Fig. 3 Typical gas chromatograms of sulfur compounds in the ICU room air

Sample gas (0.5 l) cold-trapped with liquid oxygen. Peak 1. carbon dioxide; 2 . carbonyl sulfide;

3. hydrogen sulfide $(1.2 \mathrm{ppb}) ; 4$. carbon disulfide. Sample taken on Dec. 27, 1990, 3:22p.m.-3:25p.m. The other GC conditions are listed in Table 3 , condition 1 . 
pounds, i.e., carbonyl sulfide, hydrogen sulfide and carbon disulfide, were detected in the background air sample. Of the detected sulfur compounds, the detected concentration and odor recognition threshold values of hydrogen sulfide were $1.2 \mathrm{ppb}$ and $5.6 \mathrm{ppb}$, respectively. Therefore, the sulfur compound levels were not significantly lower than the odor recognition threshold values. Hoshika et al ${ }^{19)}$ have reported FPD gas chromatographic determination using of trace concentrations of these three sulfur compounds at ppb levels in urban air in the Nagoya area using the cold trapping method with liquid oxygen cooling. However, the same odor of rotten eggs or decaying cabbage was not perceived by olfaction in the ICU room air.

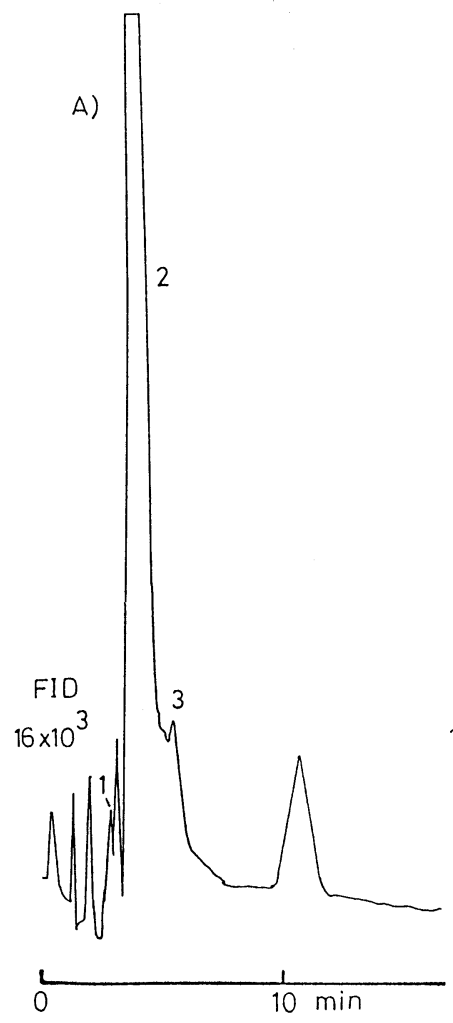

Figure 4A shows typical gas chromatograms of oxygenates of acetaldehyde (1), ethanol (2) and acetone (3) in the ICU room air. Figure 4B shows a typical gas chromatogram of the same sample gases collected in the cold trapping precolumn (Chromosorb W) using liquid oxygen, after passage through the 2,4-dinitrophenylhydrazine reaction precolumn. The volume concentrated to produce the chromatograms shown in Fig. 4A and $\mathrm{B}$ was $0.5 \mathrm{l}$ at room temperature. In these chromatograms, the peaks due to acetaldehyde and acetone have decreased. Acetaldehyde (44.7 $\mathrm{ppb})$ and acetone (22.0 ppb) were identified and quantitated by the disappearance method 10,11 ) from the peaks between the chromatogram obtained using the cold trapping alone and that ob-

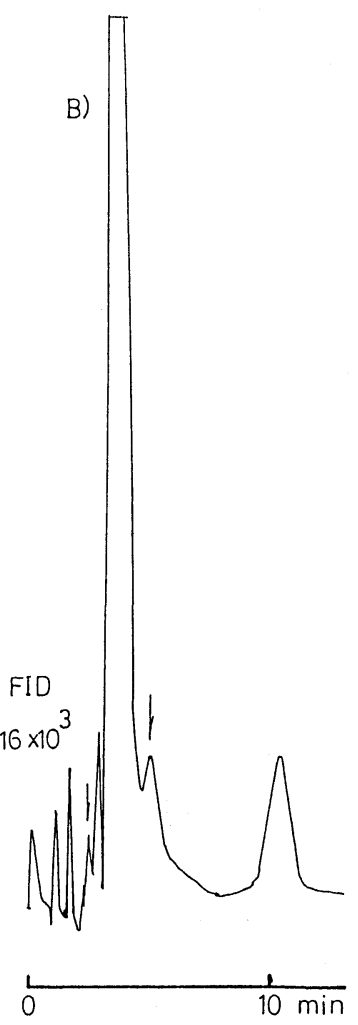

Fig. 4 Ty pical gas chromatograms of oxygenates in the ICU room air

A. Sample gas concentrated to 0.51 by the cold trapping method with liq. $\mathrm{O}_{2}$ Peak 1. acetaldehyde (44.7 ppb); 2. ethanol $(19710 \mathrm{ppb}) ; 3$. acetone $(22.0 \mathrm{ppb})$ B. Sample gas concentrated to 0.51 by the cold trapping with liq. $\mathrm{O}_{2}$, but passed through a 2,4-dinitrophenyl-hydrazine plus ortho phosphoric acid reaction precolumn. The other GC conditions are listed in Table 3, condition 2. 
tained using the cold trapping plus the 2,4-dinitrophenylhydrazine reaction precolumn as described in the caption to Fig. 4.

The detected concentrations and odor recognition threshold values of acetaldehyde and acetone were as follows: $44.7 \mathrm{ppb}$ and $15 \mathrm{ppb} ; 22.0$ ppb and $110000 \mathrm{ppb}$, respectively. Therefore, the detected concentration of acetaldehyde was significantly higher than the odor recognition threshold value. Gas chromatography of 15 liters of ICU room air was also carried out using the 2,4-dinitrophenylhydrazone derivatization meth$\mathrm{od}^{20)}$. The reactions between 2,4-dinitrophenylhydrazine and acetaldehyde and acetone are highly specific. The obtained 2,4-dinitrophenylhydrazones were directly separated by OV -17 column gas chromatography and the peaks of 2,4dinitrophenylhydrazones of acetaldehyde and acetone were separated and identified. Hoshika ${ }^{11)}$ has reported ranges and average concentrations of acetaldehyde in urban air samples (from the Nagoya area) of 1.5 to $9.6 \mathrm{ppb}$ and $4.7 \mathrm{ppb}$, respectively. Recognizable alcoholic and faint pungent odors were perceived by olfaction in the ICU room air.

Figure 5 shows the typical hydrocarbons in the ICU room air. These hydrocarbon concentrations were at the background air level .

Figure 6 shows a typical gas chromatogram of phenol in the ICU room air. The concentration detected was at the background air level.

The detected concentration and odor recognition threshold value were $2.3 \mathrm{ppb}$ and $59 \mathrm{ppb}$, respectively. Therefore, the phenol level was significantly lower than the odor recognition threshold value.

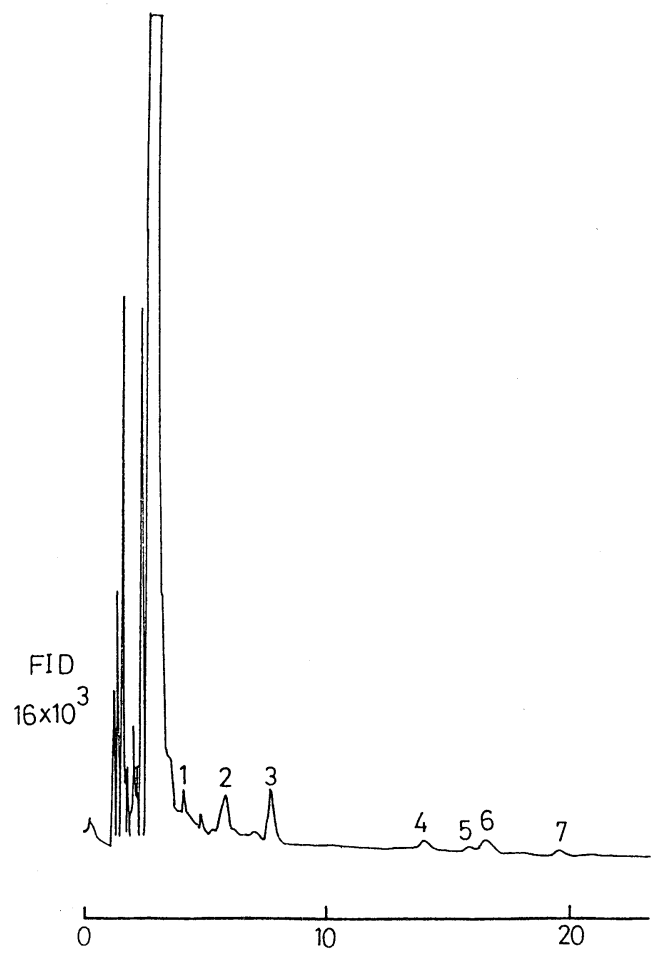

Fig. 5 Typical gas chromatogram of hydrocarbons in the ICU room air Sample gas $(0.5 \mathrm{l})$ cold trapped with liq. $\mathrm{O}_{2}$.

Peak 1. n-hexane $(2.4 \mathrm{ppb}) ; 2$. benzene $(8.3 \mathrm{ppb}) ; 3$. toluene $(9.9 \mathrm{ppb})$; 4 . ethyl benzene $(7.0 \mathrm{ppb}) ; 5 . \mathrm{p}$-xylene $(1.9 \mathrm{ppb}) ; 6 . \mathrm{m}$-xylene $(3.0 \mathrm{ppb}) ; 7$. o-xylene $(2.0 \mathrm{ppb})$ The other GC conditions are listed in Table 3 , condition 3. 


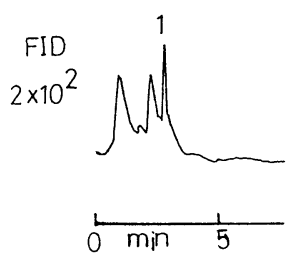

Fig. 6 Typical gas chromatogram of phenol in the ICU room air

Sample gas (2 l) adsorption trapping at room temperature with a Tenax-GC precolumn reconcentrated with an XE-60 precolumn. Peak 1. phenol (2.3 ppb)

The other GC conditions are listed in Table 3, condition 4 .

Hoshika et $\mathrm{al}^{21)}$ have reported ranges and average concentrations of phenol in samples of urban air from the Nagoya area, finding in $5 \mathrm{l}$ of concentrated air $0.05-2.3 \mathrm{ppb}$ and $0.44 \mathrm{ppb}$, respectively.

Figure 7 shows a typical gas chromatogram of lower fatty acids in the ICU room air. The procedures for the collection of the sample gas and for the analysis of the acids concentrated are described in Experimental. Position a represents the precolumn heating to $200^{\circ} \mathrm{C}$ in the carrier gas line and position $b$ represents the injection point for the formic acid aqueous solution at $200^{\circ} \mathrm{C}$.

Hoshika $^{9)}$ has reported on lower fatty acids in urban air from the Nagoya area. The volume concentrated was $50 l$ and the ranges and concentrations of the lower fatty acids detected were as follows: acetic acid, 0.837-2.93 ppb (av. 1.69 $\mathrm{ppb}$ ); propionic acid, 0.0393-0.263 ppb (av . $0.102 \mathrm{ppb}$ ); iso-butyric acid, 0.0026-0.0243 ppb (av . 0.0089 ppb); n-butyric acid, 0.0095-0.056 ppb (av. 0.0253 ppb) ; iso-valeric acid, 0.0006$0.0041 \mathrm{ppb}$ (av. 0.0025 ppb);n-valeric acid, 0.0038-0.0299 ppb (av. 0.0139 ppb). Faint to recognizable odor levels due to the lower fatty acids were perceived, i.e., rancid, putrid, faecal, pungent and sour odors were present in the ICU room.

All of the odor recognition threshold values used in this study have been cited previously, and the values were determined in an odor-free room ${ }^{22,23)}$.

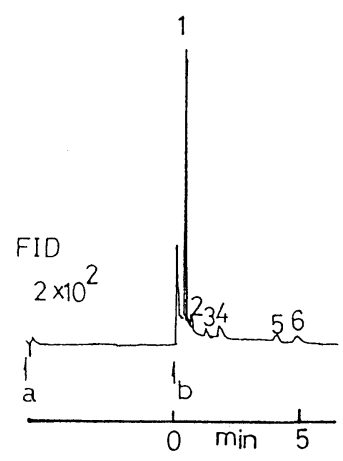

Fig. 7 Typical gas chromatogram of lower fatty acids in the ICU room air

Sample gas $(2.5 \mathrm{l})$ collected in the precolumn packed with adsorbent preconditioned and regenerated from the precolumn with formic acid aqueous solution. Position a represents the precolumn heating to $200^{\circ} \mathrm{C}$ in the carrier gas line and position b represents the injection point of the formic acid aqueous solution at $200^{\circ} \mathrm{C}$

Peak 1. acetic acid (12.8 ppb); 2. propionic acid (0.68 $\mathrm{ppb})$; 3 . iso-butyric acid $(0.35 \mathrm{ppb}) ; 4$. n-butyric acid $(0.50 \mathrm{ppb}) ; 5$. iso-valeric acid $(0.45 \mathrm{ppb})$;

6. $\mathrm{n}$-valeric acid (0.67 ppb)

The other GC conditions are listed in Table 3, condition 5 .

\section{API-MS data.}

Figure 8 shows the typical API-MS spectra of the ICU room air.

The peaks at $\mathrm{m} / \mathrm{z} 19,37$ and 55 corresponded to protonated water clusters of $\left(\mathrm{H}_{2} \mathrm{O}\right) \mathrm{H}^{+}$, $\left(\mathrm{H}_{2} \mathrm{O}\right)_{2} \mathrm{H}^{+}$and $\left(\mathrm{H}_{2} \mathrm{O}\right){ }_{3} \mathrm{H}^{+}$, respectively. The peak at $\mathrm{m} / \mathrm{z} 47$ was due to $\left(\mathrm{C}_{2} \mathrm{H}_{5} \mathrm{OH}\right) \mathrm{H}^{+}$, and that of 59 due to $\left(\left(\mathrm{CH}_{3}\right)_{2} \mathrm{CO}\right) \mathrm{H}^{+}$(acetone trace). The main component of the oxygenates in the ICU room air was ethanol. The repeatability of the API-MS counts of the voltages for 1-10ppm of ethanol $(\mathrm{m} / \mathrm{z} 47)$ in air were evaluated. They showed good uniformity and repeatability in relative standard deviation of less than about $8 \%$.

The concentration of methane in the ICU room air was at about the background air level of $1.5 \mathrm{ppm}$, and that of ammonia was less than $1 \mathrm{ppm}$. The concentrations of methane and ammonia in the ICU room air were determined by using an flame ionization detection-gas chromato- 
A) VGAIN 1

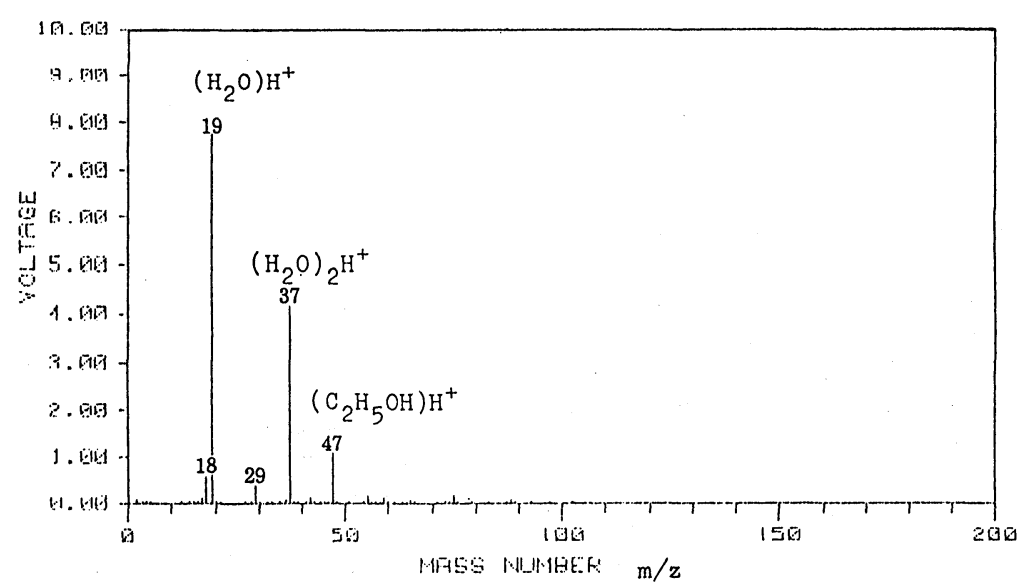

B) VGAIN 10

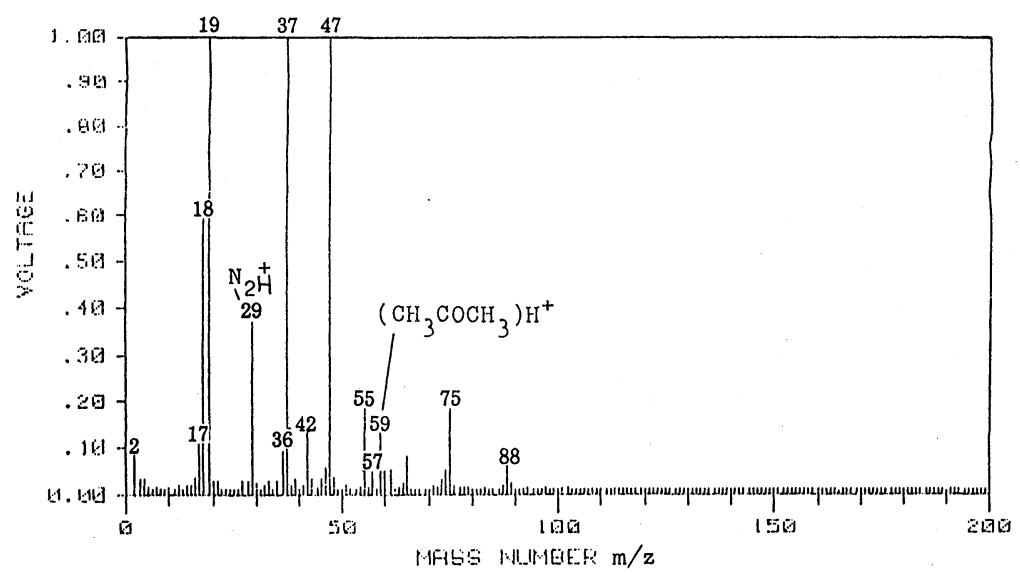

Fig. 8 Typical API-MS spectra of odorants in the ICU room air

The peaks at $\mathrm{m} / \mathrm{z}$ due to $17,\left(\mathrm{CH}_{4}\right) \mathrm{H}^{+}$or $\mathrm{NH}_{3}{ }^{+} ; 18,\left(\mathrm{H}_{2} \mathrm{O}\right)^{+}$or $\left(\mathrm{NH}_{3}\right) \mathrm{H}^{+} ; 19,\left(\mathrm{H}_{2} \mathrm{O}\right) \mathrm{H}^{+}$; 28, $\mathrm{N}_{2}{ }^{+} ; 37,\left(\mathrm{H}_{2} \mathrm{O}\right){ }_{2} \mathrm{H}^{+} ; 47,\left(\mathrm{C}_{2} \mathrm{H}_{5} \mathrm{OH}\right) \mathrm{H}^{+} ; 55,\left(\mathrm{H}_{2} \mathrm{O}\right){ }_{3} \mathrm{H}^{+} ; 59,\left(\mathrm{CH}_{3} \mathrm{COCH}_{3}\right) \mathrm{H}^{+}$; and others. Sample taken on Dec. 27, 1990; 3:22p.m. -3:25p.m.

The optimum conditions for this instrument are as follows: initial mass, 2; scanning speed, $1.6 \mathrm{~ms}$; final mass, 200; repeat, 2; SGAIN, $10^{-8}(\mathrm{~A} / \mathrm{V})$; ion source temperature, $140^{\circ} \mathrm{C}$; sample introduction flow rate, $0.3 \mathrm{l} / \mathrm{min}$, drift voltages, $40 \mathrm{~V}$.

graphy and a detector tube, respectively .

\section{Characterization of odorants in the ICU room} air.

Table 4 lists the detected concentrations of the odorants in the ICU room air and the values for all the parameters as defined in an earlier report ${ }^{8)}$.

(A) The detected concentrations $\left(\mathrm{C}_{\mathrm{n}}, \mathrm{ppb}\right)$ of the respective odorants belonging to the seven odorant groups from the ICU room air.

(B) The recognition threshold value (R.Th. $V_{n}$, $\mathrm{ppb}$ ) of the respective detected odorants. All of these values were obtained from two reports that determined them using an odor-free room ${ }^{22,23)}$. (C) The odor units (OU, $\mathrm{C}_{\mathrm{n}} \mathrm{ppb} / \mathrm{R} . \mathrm{Th} . \mathrm{V}_{\mathrm{n}} \mathrm{ppb}$ ) of the detected odorants vs. the corresponding odor recognition threshold values (in ppb) of the odorants. 
Table 4 Detected concentrations $\left(C_{n}, p p b\right)$, recognition threshold values (R.Th.Vn, ppb), OU, log OU, pOUm and pOUa of seven odorant groups in the Shinshu University School of Medicine Hospital ICU room air

\begin{tabular}{|c|c|c|c|c|c|c|}
\hline Group & Compounds & (A) $C_{n}(p p b)$ & $\begin{array}{l}\text { (B) } \mathrm{R} \cdot \mathrm{Th} \cdot \mathrm{Vn}^{\mathrm{a}} \\
(\mathrm{ppb})\end{array}$ & (C) $\mathrm{OU}$ & (D) $\log \mathrm{OU}$ & $\begin{array}{l}\text { (E) pOUm } \\
\text { (F) (pOUa) }\end{array}$ \\
\hline ( I ) RSR & Hydrogen sulfide & 1.2 & 5.6 & - & - & 0 \\
\hline (II) $\mathrm{R}_{3} \mathrm{~N}$ & Ammonia & $<500$ & 600 & - & - & 0 \\
\hline \multirow[t]{2}{*}{ (III) $\mathrm{RCOR}$} & Acetaldehyde & 44.7 & 15 & 2.98 & 0.48 & 0.48 \\
\hline & Acetone & 22.0 & 110000 & - & - & $(0.48)$ \\
\hline \multirow[t]{7}{*}{ (IV) $\mathrm{HC}^{*}$} & n-Hexane & 2.4 & - & - & - & \\
\hline & Benzene & 8.3 & $4680^{b}$ & - & - & \\
\hline & Toluene & 9.9 & 4800 & - & - & \\
\hline & Ethyl benzene & 7.0 & - & - & - & 0 \\
\hline & p-Xylene & 1.9 & 520 & - & - & \\
\hline & m-Xylene & 3.0 & 560 & - & - & \\
\hline & o-Xylene & 2.0 & 720 & - & - & 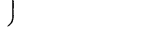 \\
\hline (v) $\mathrm{ROH}$ & Ethanol & 19710 & 6100 & 3.23 & 0.51 & $\begin{array}{c}0.51 \\
(0.51)\end{array}$ \\
\hline (VI) $\mathrm{PhOH}$ & Phenol & 2.3 & 59 & - & - & 0 \\
\hline \multirow[t]{6}{*}{ (VII) $\mathrm{RCOOH}$} & Acetic acid & 12.8 & $1000^{\mathrm{b}}$ & - & - & \\
\hline & Propionic acid & 0.68 & 8.4 & - & - & \\
\hline & iso-Butyric acid & 0.35 & 1.3 & - & - & \\
\hline & n-Butyric acid & 0.50 & 0.4 & 1.25 & 0.09 & 0.32 \\
\hline & iso-Valeric acid & 0.45 & 0.4 & 1.13 & 0.05 & \\
\hline & n-Valeric acid & 0.67 & 0.5 & $\begin{array}{c}1.34 \\
\text { (OU)t } 3.72\end{array}$ & 0.18 & $(0.57)$ \\
\hline
\end{tabular}

a : Values quoted from reference ${ }^{22}$.

b : Values quoted from reference ${ }^{23)}$.

* : $\mathrm{HC}$ represents hydrocarbons. $\quad$ pOUa : Figures in paraentheses are pOUa values.

(D) The logOU values of the detected odorants.

(E) The $\mathrm{pOU}_{\mathrm{m}}=\log \mathrm{OU}_{1}+\log \mathrm{OU}_{2}+\cdots \ldots \ldots$

(F) The pOU $\mathrm{a}=\log \mathrm{OU}_{\mathrm{t}}$

$$
+\log \mathrm{OU}_{\mathrm{n}}
$$

In Table 4, when the odor recognition threshold values of the detected odorants are unknown and the ratios of the detected concentration, in $\mathrm{ppb}$, vs. the corresponding odor recognition threshold value (in $\mathrm{ppb}$ ), i.e., the OU values, are less than 1.0 , the odor unit (OU) values of the detected odorants are defined as minus $(-)$; therefore, the logOU values of the detected odorants are also defined as minus (-). Furthermore, when the logOU values of all the detected odorants in the same odorant group are minus $(-)$, the pOU value of the odorant group is defined as zero $(0)$.

The detected concentrations of acetaldehyde, ethanol, $n$-butyric acid, iso-valeric acid and $\mathrm{n}$-valeric acid were significantly higher than the odor recognition threshold values. The main odorant component in the ICU room air was ethanol, and the ratio (OU) of the detected concentration to the recognition threshold value was also the highest for these odorants in the ICU room air.

These compounds may, therefore, be responsible for the faint or recognizable, alcoholic, disinfectant, sour, rancid, pungent and goaty odors. A faint mixed body odor, sweet, sulfurlike, pungent, green-sweet, so-called characteristic body odor or disinfectant alcohol odor (c.f . $76.9-81.4 \% \mathrm{v} / \mathrm{v}$ ethanol, $500 \mathrm{ml} \times 20 /$ week) was perceived by olfaction in the ICU room .

\section{Conclusion}

A sensory test, gas chromatography and API-MS for odors and odorants in air in a real 
ICU room were carried out. The trace amounts of the odorants detected in the air were classified into seven groups and were analyzed by routine systematic gas chromatographic techiques. The detected concentrations of acetaldehyde, ethanol and lower fatty acids were significantly higher than the odor recognition threshold values. These compounds may, therefore, be responsible for odors such as the odor of alcohols used for disinfection. Faint, sweet, sulfur-like, pungent, green-sweet odors were perceived by olfaction in the ICU room. The odor level in the ICU room was low or at the faint or recognizable level for, acetaldehyde, ethanol, $\mathrm{n}$-butyric acid, iso-valeric acid and n-valeric acid.

\section{Acknowledgement}

The author thanks Prof. Dr. Ninzo Murayama, Prof. Dr. K. Kobayashi and C.N. A. Futatsugi, Shinshu University School of Medicine, Hospital, for useful suggestions and expresses their thanks to Mr. S. Nakajima, I. Mizogami and K. Hasumi, Hitachi Tokyo Electronics Ltd., Tokyo, Japan for technical assitance.

\section{References}

1) Hayden, C.F.: Olfactory diagnosis in medicine, Postgrad. Med., 67, 110-118 (1980).

2 ) Manolis, A.: The diagnostic potential of breath analysis, Clin. Chem., 29, 5-15 (1983).

3 ) Environment Agency: Air Pollution Control in Japan, pp.12, 24-25, Offensive Odor, Offensive Odor Control Law (1972).

4 ) Katz, S.H. and Talbert, E.J. : Intensity of odor and irritating effects of warning agents for inflammable and poisoning gases, U.S. Dept. Commerce, Techn. Paper, 480 (1930).

5 ) Summer, W : : Methods of Air Deodorization, pp.306-309, Elsevier Pub. Com., Amsterdam (1963).

6 ) Hoshika, Y. and Muto, G.: An investigation on characterization of trace odorants in air by gas chromatography using precon- centration. Its evaluation and application, Bunseki Kagaku, 29, T10-T19 (1980) . (in Japanese with English abstract)

7 ) Hoshika, Y., Nihei, Y. and Muto, G.: Simple circular odor chart for characterization of trace amounts of odorants discharged from thirteen odor sources, J. Chromatogr. Sci., 19, 200-215 (1981).

8 ) Hoshika, Y., Nihei, Y. and Muto, G.: Pattern display for characterisation of trace amounts of odorants discharged from nine odor sources, Analyst (London), 106, 1187-1202 (1981).

9 ) Hoshika, Y.: Gas chromatographic determination of lower fatty acids in air at partper-trillion levels, Anal. Chem ., 54, 2433-2437 (1982).

10) Hoshika, Y. : Simple and rapid gas chromatographic determination of trace amounts of lower aliphatic carbonyl compounds in exhaust gases from some odour sources, Analyst (London), 106, 686-694 (1981).

11) Hoshika, Y. : Simple and rapid gas-liquidsolid chromatographic analysis of trace concentrations of acetaldehyde in urban air, J. Chromatogr . , 137, 455-460 (1977).

12) Kato, T.: Taikiosen no gasukuromatogijutsu [Gas chromatographic techniques on air pollution], p.297, Sankyo Shuppan, Tokyo (1975). (in Japanese)

13) Horning, E.C., Horning, M.G., Carroll, D.I., Dzidic, I. and Stillwell, R.N. : New picogram detection system based on a mass spectrometer with an external ionization source at atmospheric pressure, Anal. Chem., 45, 936-943 (1973).

14) Carroll, D.I. , Dzidic, I., Stillwell, R.N. , Horning, M.G. and Horning, E.C. : Subpicogram detection system for gas phase analysis based upon atmospheric pressure ionization (API-MS), mass spectrometry, Anal . Chem., 46, 706-710 (1974).

15) Horning, E.C., Carroll, D.I., Dzidic, I. , Haegele, K. D. , Horning, M.G. and Still- 
well, R.N.: Liquid chromatographic-mass spectrometer-computer analytical system. A continuous-flow system based on atmospheric pressure ionization mass spectrometry, J. Chromatogr. , 99, 13-21 (1974).

16) Dzidic, I., Carroll, D.I., Stillwell, R.N. and Horning, E.C.: Atmospheric pressure ionization (API) mass spectrometry . Formation of phenoxide ions from chlorinated aromatic compounds, Anal. Chem., 47, 1308-1312 (1975).

17) Kambara, H. and Kanomata, I.: Determination of impurities in gases by atmospheric pressure ionization mass spectrometry, Anal. Chem. , 49, 270-275 (1977).

18) Sunner, J., Ikonomou, M.G. and Kebarle, P. : Sensitive enhancements obtained at high temperature atmospheric pressure ionization mass spectrometry, Anal. Chem ., 60, 1308-1313 (1988).

19) Hoshika, Y., Kozima, I., Koike, K. and Yoshimoto, K.: The gas chromatographic analysis of the trace concentrations of sul- fur compounds in the urban air, Bunseki Kagaku, 23, 1393-1398 (1974). (in Japanese with English abstract)

20) Hoshika, Y. and Takata, Y.: Gas chromatographic separation of carbonyl compounds as their 2,4-dinitrophenylhydrazones using glass capillary columns, J. Chromatogr. , 120, 379-389 (1976) .

21) Hoshika, Y. and Muto, G.: Gas-liquidsolid chromatographic determination of phenols in air using Tenax-GC and alkaline precolumns, J. Chromatogr. , 157, 277-284 (1978) .

22) Japan Environment Agency: Reports of studies on the measurements of the offensive odors, 1972-1980, Japan Enviroument Agency, Tokyo (1980) . (in Japanese)

23) Leonardos, G., Kendall, D. and Barnard, N.: Odor threshold determination of 53 odorant chemicals, J. Air Pollut. Control Assoc. , 19, $91-95$ (1969).

(Received May 8, 1992/Accepted Apr. 12, 1993) 